Revista de Economia Política, vol. 32, no 1 (126), pp. 33-54, janeiro-março/2012

\title{
Brasil (1955-2005): \\ 25 anos de catching up, 25 anos de falling behind
}

\author{
MARCELO AREND \\ PEDRO CEZAR DUTRA FONSECA*
}

Brazil (1955-2005): 25 years of catching-up, 25 years of falling behind. The present paper discusses the Brazilian industrial development under a neo-schumpeterian perspective in the period after 1955. The hypothesis is that, in the last 50 years, Brazil spent the first 25 years catching $u p$ and, next, the following 25 years falling behind. The 1955-1980 period, by means of international funding, allowed catching up with the paradigm in maturation within the fourth technological revolution. However, in this period, it was determined the main debilitating elements for the country's entrance in the new techno-economical paradigm of the fifth technological revolution which emerged in the middle of the 70s. It is in the strategy to internationalize the economy, granting the mutinational companies the key-sectors of the national economy dynamics during the catching up period, the main element of dependence in the journey that conditions the current performance, responsible for technology subordination and keeps the Brazilian economy with low dynamism.

Keywords: Brazilin industrialization; catching up strategies; technological change.

JEL Classification: O14; O33; O54.

\section{INTRODUÇÃO}

Atualmente, para muitos pesquisadores da Escola Neoschumpeteriana, é possível dividir a evolução histórica do capitalismo em cinco revoluções tecnológicas. Cada revolução tecnológica traz consigo nova reorganização da estrutura produtiva e a ocorrência de modos de crescimento sucessivos e distintos. A percepção da

\footnotetext{
* Professor adjunto do Departamento de Ciências Econômicas da UFSM. E-mail: marceloarend@yahoo. com.br. Professor Titular do Departamento de Ciências Econômicas da UFRGS, pesquisador do CNPq. E-mail: pedro.fonseca@ufrgs.br. Submetido:3/março/2011; Aprovado: 16/setembro/2011.
} 
ocorrência de modos de crescimento distintos baseia-se no entendimento de que a cada revolução tecnológica emerge um novo paradigma tecnoeconômico, que promove um salto quântico de produtividade e novas possibilidades para trajetórias econômicas nacionais. Um novo paradigma tecnoeconômico abre novas oportunidades para alguns países tomarem a liderança do desenvolvimento (forging ahead) e para outros se emparelharem (catching up) com países mais desenvolvidos. Entretanto, alguns países também podem não se engajar na nova dinâmica, ficando para trás na trajetória de desenvolvimento (falling behind). Para a abordagem neoschumpeteriana, a inserção ou o não ingresso de um país de forma dinâmica à revolução tecnológica em vigor é fator fundamental para o entendimento dos processos de desenvolvimento desigual, avanço/atraso tecnológico e alto/baixo dinamismo de longo prazo de economias nacionais.

Nos últimos 50 anos, o desempenho dos países capitalistas não tem sido homogêneo e tampouco as trajetórias nacionais de desenvolvimento dos países periféricos têm revelado um processo de convergência. Conforme mostra o Gráfico 1, apesar da participação no PIB global dos países em desenvolvimento ser crescente no último meio século, tendo estes até mesmo superado a participação dos países desenvolvidos no ano de 2005, quando se apresentam informações particulares de regiões e países específicos percebe-se que na realidade não ocorre um processo universal de convergência.

De 1950 até 1980 os ganhos de participação no PIB global ficaram por conta principalmente dos países da América Latina, tendo como destaque o desempenho da economia brasileira. Nesse período $75 \%$ do ganho de participação latino-americano no PIB global deveu-se ao Brasil. Os 25 anos posteriores revelaram uma dinâmica extremamente distinta: praticamente todo o ganho de participação dos países em desenvolvimento no PIB global coube apenas à Ásia em desenvolvimento, com destaque para o desempenho dos NICS (Coreia do Sul, Taiwan, Hong Kong e Cingapura) e da China. No ano de 2005, a América Latina teve uma participação no PIB global equivalente à do ano de 1950. Em grande medida, esse regresso foi fortemente influenciado pela perda de participação do Brasil no PIB global, que em 2005 apresentou um peso na economia mundial equivalente ao da década de 1970. Nesse sentido, para a América Latina, e em especial para o Brasil, o desempenho do período 1950-1980 jamais foi retomado, sendo marcante as perdas dos últimos 25 anos. 


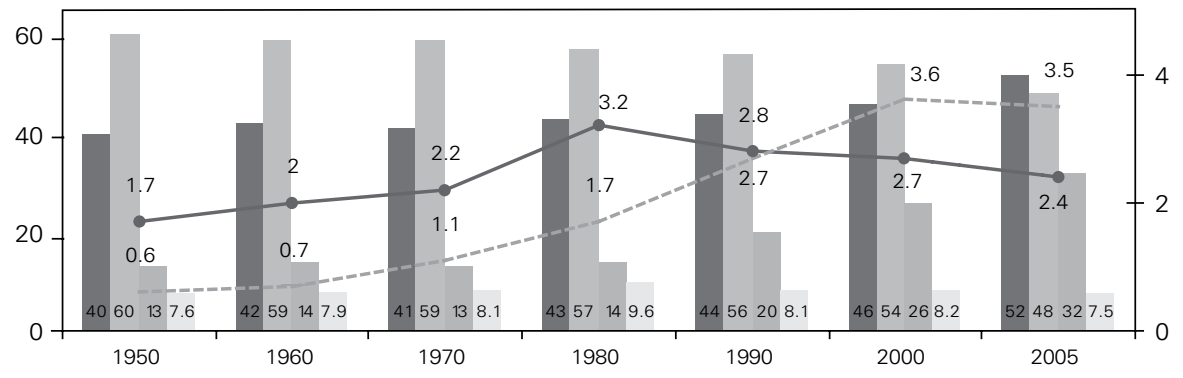

\begin{tabular}{|c|c|c|}
\hline Países em Desenvolvimento & Países Desenvolvidos & Ásia em Desenvolvimento \\
\hline América latina & $\longrightarrow$ Brasil & $=-=$ NICS \\
\hline
\end{tabular}

Fonte: Elaborado a partir de http://www.ggdc.net.

O artigo tem o propósito de analisar os últimos 50 anos de desempenho econômico brasileiro. Baseado no modelo histórico-analítico de Perez (2004), sobre ondas longas de desenvolvimento, nossa pesquisa indica que os últimos 50 anos de desempenho industrial brasileiro foram extremamente influenciados pelas dinâmicas particulares das duas últimas revoluções tecnológicas e pelo padrão típico dos fluxos internacionais de capitais dessas duas revoluções. O estudo mostra que o Brasil conseguiu promover seu catching up (1955-1980) a partir de uma estratégia de crescimento alicerçada no aporte de recursos externos. Entretanto, a partir da década de 1980 a irrupção da quinta revolução tecnológica expôs a vulnerabilidade desta estratégia, a qual delegava ao capital estrangeiro os setores mais dinâmicos do processo de industrialização em marcha, responsabilizando-o crescentemente pelo financiamento do crescimento nacional.

$\mathrm{O}$ artigo está estruturado da seguinte forma. $\mathrm{Na}$ segunda seção apresenta-se resumidamente o modelo histórico-analítico de Perez (2004). Na terceira seção, o intuito é mostrar que a economia brasileira durante o período 1955-1980 realizou seu catching up beneficiando-se da dinâmica da fase final da quarta revolução tecnológica. Também, indica-se que nos últimos 25 anos (1980-2005) a economia brasileira ingressou em um processo de falling behind, o qual foi fortemente influenciado pela dinâmica tecnológica e financeira da fase inicial do quinto paradigma tecnoeconômico. Atraso tecnológico, vulnerabilidade externa, desindustrialização precoce e reespecialização produtiva são evidências que permitem afirmar que o Brasil, desde 1980, vem ficando para trás na trajetória de desenvolvimento capitalista. Na quarta seção enfatiza-se que o caminho escolhido durante o período 1955-1980 acabou gerando uma dinâmica de baixo dinamismo de longo prazo, e que o país parece ter ficado aprisionado (lock-in) a uma estratégia de crescimento com poupança externa no longo prazo. 


\section{E A DINÂMICA ENTRE O CAPITAL PRODUTIVO E O CAPITAL FINANCEIRO NAS REVOLUÇÕES TECNOLÓGICAS}

Nesta seção busca-se apresentar a relação entre o capital financeiro e o capital produtivo ao longo das fases de um paradigma tecnoeconômico. Sugere-se que, na primeira metade de uma onda longa de desenvolvimento, as ideias econômicas historicamente pendem para o liberalismo e que esse período é caracterizado pela dominância financeira. Também se mostra que, nesse período, a revolução tecnológica tende a gerar uma bolha tecnológica-financeira, seguida de colapso financeiro. Após o colapso, segue-se um momento de rearranjo institucional, definidor do estilo de crescimento da segunda metade da onda longa, geralmente caracterizado pelo domínio do capital produtivo e do ideário intervencionista do Estado.

A Figura 1 ilustra os principais elementos teóricos do modelo histórico-analítico proposto por Perez (2004). As revoluções tecnológicas e seus respectivos paradigmas apresentam dois períodos distintos em sua evolução. O primeiro período, denominado de Instalação, corresponde aos primeiros 20-30 anos iniciais do paradigma tecnoeconômico. As duas ou três décadas seguintes correspondem ao período denominado de Desprendimento (ou dispersão), caracterizado pela disseminação completa da revolução tecnológica. Todavia, cada um desses períodos é subdividido em duas fases: a primeira fase do período de instalação é denominada de "irrupção"; e a segunda, de "frenesi". As fases do período de desprendimento são respectivamente denominadas de "sinergia" e "maturidade". Fundamental também é perceber que ao redor da metade de uma revolução tecnológica, depois do período de instalação e antes do período de desprendimento, há um interregno denominado pela autora de "intervalo de reacomodação", cuja periodicidade varia em cada revolução, podendo ser de poucos anos até uma década ou mais.

No primeiro período (Instalação), a fase caracterizada pela irrupção de novas tecnologias, revolucionárias, anuncia o salto quântico de produtividade potencial. É interessante notar que, nessa fase, há uma sobreposição entre as revoluções: da "antiga" revolução, já em maturidade, com a que está surgindo e que prenuncia a chegada de uma "nova economia". À medida que começa a diminuir as oportunidades de investimentos de baixo risco (da revolução tecnológica em vigor) e os mercados se encontram saturados, uma massa crescente de "capital ocioso" busca usos alternativos, capazes de proporcionar maiores lucros, e se dispõe a se aventurar em direções novas. Seu papel é romper com as trajetórias rotineiras e facilitar mudanças radicais. É nesse período que a separação entre o capital financeiro e o capital produtivo rende seus melhores frutos. $\mathrm{Na}$ fase de irrupção, o capital financeiro realiza seu "casamento" com um novo capital produtivo, emergente, pois as 
novas técnicas superam o potencial de geração de riqueza de qualquer capital até então estabelecido. ${ }^{1}$

Figura 1: Sequência Recorrente na Relação entre o Capital Financeiro e o Capital Produtivo em uma Onda Longa de Desenvolvimento

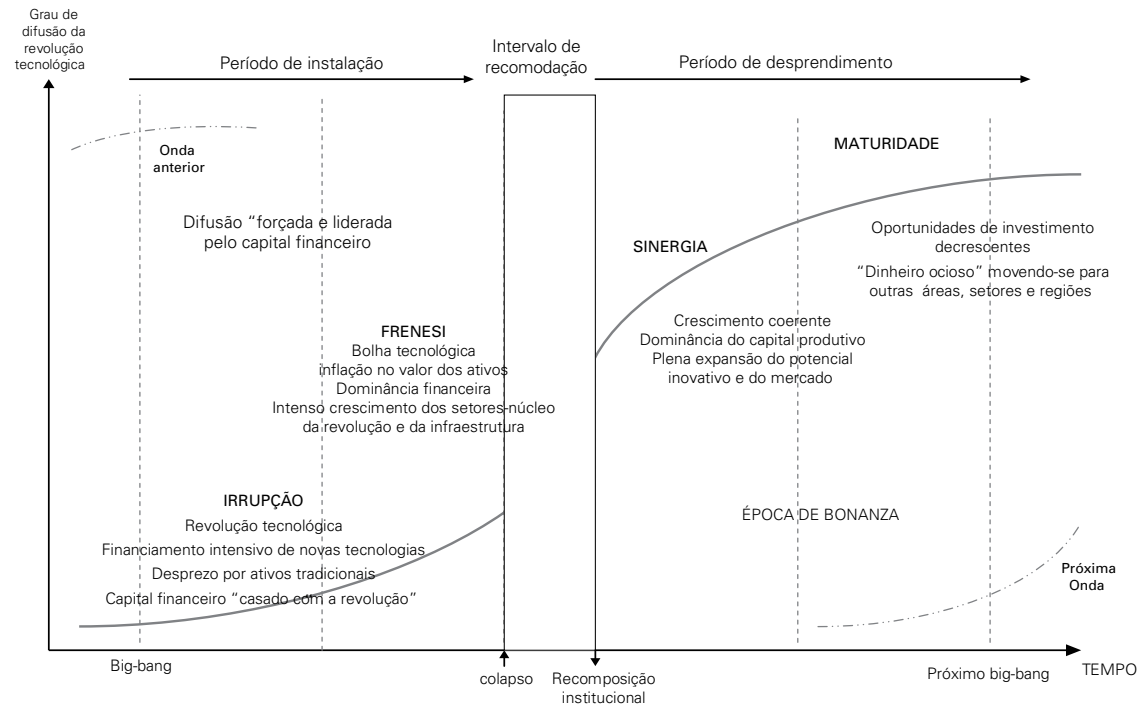

Fonte: Elaborada a partir de Perez (2004, p. 109).

A segunda fase do período de instalação marca o comportamento frenético do capital financeiro. Seu interesse por lucros associados à nova revolução tecnológica termina por provocar uma bolha tecnológico-financeira, aparente nas altas generalizadas dos preços dos ativos financeiros, que geralmente conduz a um colapso financeiro.

Para Perez (2004), são nas fases denominadas de frenesi que as ideias econômicas pendem para o liberalismo, quando se acredita que o laissez-faire é capaz de comandar os acontecimentos rumo a uma "nova economia". Geralmente, nas duas-três primeiras décadas de uma onda longa, o capital financeiro impera, e percebe-se cada vez mais uma "economia de cassino". Assim, os colapsos financeiros históricos verdadeiramente grandes ocorrem duas ou três décadas após o início de cada revolução industrial. Conforme o Quadro 1, à parte da relativa regularidade temporal, é interessante notar que essas bolhas tecnológico-financeiras tendem a levar o nome da infraestrutura da revolução correspondente.

\footnotetext{
${ }^{1}$ Essa é a contribuição mais original do modelo histórico-analítico de Perez (2004), pois permite examinar a interação entre o capital financeiro e as ondas de novas tecnologias, baseando-se na ideia de que é possível encontrar regularidades dinâmicas e sequências de mudanças recorrentes no funcionamento do capitalismo.
} 
Quadro 1: Cinco Ondas Sucessivas, Períodos Recorrentes

Paralelos e Principais Crises Financeiras

\begin{tabular}{|c|c|c|c|c|c|}
\hline \multirow{2}{*}{$\begin{array}{l}\text { Revolução } \\
\text { Tecnológica } \\
\text { onda longa }\end{array}$} & \multicolumn{2}{|c|}{ Instalação } & \multirow{2}{*}{$\begin{array}{c}\text { Intervalo de } \\
\text { reacomodação } \\
\text { Colapso financeiro, } \\
\text { recessão e } \\
\text { recomposição pessoal }\end{array}$} & \multicolumn{2}{|c|}{$\begin{array}{l}\text { Desdobramento } \\
\text { (Dispersão) }\end{array}$} \\
\hline & $\begin{array}{l}\text { Irrompimento } \\
\text { Big-bang }\end{array}$ & $\begin{array}{c}\text { Frenesi } \\
\text { Bolha financeira }\end{array}$ & & $\begin{array}{l}\text { Sinergia } \\
\text { Boom }\end{array}$ & Maturidade \\
\hline $\begin{array}{l}\text { 1o (1771) } \\
\text { Revolução } \\
\text { Industrial }\end{array}$ & $\begin{array}{l}\text { Anos } 70 \text { e } \\
\text { início dos } 80\end{array}$ & $\begin{array}{c}\text { Mania dos } \\
\text { Canais (1793) }\end{array}$ & 1797 (pânico financeiro) & $\begin{array}{c}\text { 1798-1812; } \\
\text { Grande } \\
\text { avanço inglês }\end{array}$ & $\begin{array}{c}1813-1829 \\
\text { Crises } \\
\text { financeiras } \\
(1819 \text { e 1825) }\end{array}$ \\
\hline $\begin{array}{l}\text { 2 (1829) } \\
\text { Era do Vapor e } \\
\text { das Ferrovias }\end{array}$ & Ano 30 & $\begin{array}{c}\text { Mania das } \\
\text { Ferrovias } \\
(1836)\end{array}$ & $\begin{array}{c}1847 \text { (pânico financeiro) } \\
\text { 1848-1850 } \\
\text { (revoluções sociais) }\end{array}$ & $\begin{array}{l}1850-1857 \\
\text { Boom } \\
\text { victoriano }\end{array}$ & $\begin{array}{c}\text { 1857-1873 } \\
\text { Crises } \\
\text { financeiras } \\
(1866 \text { e 1873) }\end{array}$ \\
\hline $\begin{array}{c}\text { 3o (1875) } \\
\text { Era do Aço da } \\
\text { Eletricidade e da } \\
\text { Engenharia pesada }\end{array}$ & 1785-1884 & $\begin{array}{l}\text { Auge dos países do } \\
\text { hemisfério } \\
\text { sul-Argentina (1890) } \\
\text { EUA (1893) }\end{array}$ & $\begin{array}{c}\text { 1893-1895 } \\
1903 \\
\text { ("pânico dos ricos") }\end{array}$ & $\begin{array}{c}\text { 1895-1907 } \\
\text { belle époque }\end{array}$ & $\begin{array}{l}1908-1918 \\
\text { Crises } \\
\text { financeiras } \\
(1920)\end{array}$ \\
\hline $\begin{array}{l}\text { 4o (1908) } \\
\text { Era do petróleo, } \\
\text { Automóvel e da } \\
\text { Produção em Massa }\end{array}$ & $1908-1920$ & $\begin{array}{l}\text { Os "loucos } \\
\text { anos 20" } \\
\text { (automóveis, } \\
\text { rádio, eletricidade, } \\
\text { imóveis etc) }\end{array}$ & $\begin{array}{l}\text { Pânico financeiro } \\
\text { 1929-1933 (Europa) } \\
\text { 1929-1943 (EUA) }\end{array}$ & $\begin{array}{l}1943-1959 \\
\text { Época de ouro } \\
\text { do pós-guerra }\end{array}$ & $\begin{array}{c}\text { 1960-1974 } \\
\text { Crise } \\
\text { do petróleo } \\
\text { (1974) }\end{array}$ \\
\hline $\begin{array}{c}\text { 5o (1791) } \\
\text { Era da Informática e das } \\
\text { telecomunicações }\end{array}$ & 1971-1987 & $\begin{array}{c}\text { Mania da } \\
\text { Internet 1987-2001 } \\
\text { Ásia (1997) }\end{array}$ & $\begin{array}{c}\text { 2001-?? } \\
\text { (Nasdaq- Subprime) }\end{array}$ & $20 ? ?$ & $20 ? ?$ \\
\hline
\end{tabular}

Fonte: Elaborado a partir de Perez (2004, cap. 7).

Nota: Datas das crises e pânicos financeiros organizadas por Perez (2004) a partir de Kindleberger (1992).

As pressões mais efetivas para a mudança institucional e, especialmente, para a intervenção do Estado na economia, surgem após o colapso financeiro seguido de recessão (depressão). Como o colapso financeiro acaba por afetar a economia real, gera-se um período marcado por demandas para uma recomposição institucional, que tenderá a condicionar o desempenho econômico da segunda metade da revolução tecnológica. Isso significa, essencialmente, que se requer uma regulação adequada do capital financeiro, assim como o estabelecimento de um marco institucional que favoreça a economia real. A onda longa de desenvolvimento entra no “intervalo de reacomodação”. Após os colapsos financeiros as ideologias político-econômicas historicamente pendem para o intervencionismo do Estado, e o crescimento econômico passa a ser regido por critérios de longo prazo do capital produtivo, em detrimento dos critérios financeiros de curto prazo para o investimento.

Geralmente o Estado assume um papel destacado na segunda fase da onda longa, proporcionando o estabelecimento de um novo clima socioeconômico: da primazia financeira à produtiva, do laissez-faire à intervenção do Estado, dentre outras mudanças. Os colapsos característicos de finais de períodos de frenesi criam condições para que o Estado estabeleça regulações a favor do capital produtivo, conduzindo a um período de crescimento mais harmonioso. A recessão (ou depressão) é certamente um preço alto a pagar, mas isso é típico da natureza contraditória do capitalismo. No entanto, o conjunto de regulações e instituições arquitetado durante o "intervalo de reacomodação" de cada onda longa é único, porque tem que se adequar às características específicas do paradigma que está sendo facilitado. 
Em regra, a segunda metade de uma revolução tecnológica é caracterizada por um período de bonança e por expressões como: "o grande avanço inglês", "o boom victoriano", "a belle époque" e "os anos dourados do pós-guerra”.

Nas primeiras fases de um paradigma, as empresas emblemáticas da revolução tecnológica encontram suficientes possibilidades de rentabilidade em seus mercados domésticos, além de enfrentarem uma forte concorrência com outras empresas "schumpeterianas". Assim, durante os primeiros 20-30 anos, o investimento nas indústrias-núcleo do paradigma, em geral, se concentra nos países centrais. As oportunidades de ingresso no paradigma ampliam-se para países periféricos somente na segunda metade da onda longa de desenvolvimento dos países desenvolvidos. Países periféricos podem se beneficiar do transbordamento das indústrias que se encontram já com mercados estancados e com reduzidos ganhos de produtividade nos países centrais, via internacionalização de seu mercado interno. Nas últimas duas ou três décadas de um paradigma, a onda de crescimento geralmente se difunde para a periferia, que, até então, havia tido poucas oportunidades de se industrializar.

Todavia, deve-se ressaltar que economias periféricas podem ingressar em uma trajetória de crescente atraso tecnológico exatamente por estarem aprisionadas a um padrão de catching up dependente. Considerando a importância da história, a saída de uma situação de crescente atraso tecnológico não é simples para uma economia que ingressou na fase final de um paradigma tecnoeconômico pela internalização de empresas estrangeiras, não fortalecendo as capacitações inovativas e competitivas de suas empresas nacionais. Provavelmente, no início de um novo paradigma, a economia periférica novamente necessitará de uma energia externa (investimentos estrangeiros, empresas multinacionais) para promover seu upgrading tecnológico. No entanto, a probabilidade de que os investimentos estrangeiros transfiram tecnologias na fase inicial de um paradigma para uma economia periférica é remota. ${ }^{2}$

Ao se considerar a possibilidade de mudança técnica, não só incremental como também revolucionária, os investimentos estrangeiros diretos geram um efeito de substituição das importações somente de curto prazo, pois no país retardatário não foram internalizados os setores responsáveis pela difusão do progresso técnico

\footnotetext{
${ }^{2}$ Para Amsden (2001), a estratégia de superação do atraso tecnológico a partir do ingresso de empresas multinacionais não garante a internacionalização tecnológica no país receptor de investimentos estrangeiros diretos. Usualmente a internacionalização tecnológica em países periféricos é restrita a processos pouco inovadores. Para Chang $(2009$, p. 88$)$ a entrada de uma empresa multinacional no mercado interno de um país retardatário, por meio do investimento estrangeiro direto, pode acabar com as empresas nacionais existentes, que poderiam “crescer” em operações bem-sucedidas, sem a exposição prematura à concorrência, ou interromper o surgimento de concorrentes domésticos. Isso geralmente ocorre porque habilidades produtivas são obtidas, no curto prazo, com o investimento estrangeiro direto, uma vez que a substituição (atual e no futuro) das empresas nacionais pela subsidiária da empresa multinacional normalmente traz resultados mais produtivos que os das empresas nacionais anteriormente estabelecidas. Mas, como resultado, o nível de capacidade produtiva que o país pode obter no longo prazo se torna menor.
} 
(barreiras à entrada dinâmicas). Com a ocorrência de uma nova revolução tecnológica nos países centrais, a elasticidade-renda das importações dos países periféricos pode se alterar num período relativamente curto de tempo. Isso se deve à não internalização no país periférico das empresas e setores-chave da nova revolução tecnológica, que restringirá o crescimento em razão do fato de que elevações do consumo e do investimento provocarão um fluxo de renda ao exterior. Assim, enquanto o rejuvenescimento do aparato produtivo não se der pelo "novo" ingresso de investimentos estrangeiros, o país ver-se-á sujeito à permanente restrição de balanço de pagamentos que, de fato, passa a ter caráter estrutural. Dessa forma, o engajamento permanente a novos paradigmas é vital para períodos de prolongado crescimento e desenvolvimento econômico. ${ }^{3}$

\section{O CATHING UP BRASILEIRO NA QUARTA REVOLUÇÃO TECNOLÓGICA E SEU FALLING BEHIND DURANTE A QUINTA}

É consenso que a etapa da "industrialização pesada" no Brasil ganha fôlego na década de 1950, especialmente a partir do Plano de Metas do governo JK. Ao interpretar a industrialização nacional à luz do marco teórico neoschumpeteriano, percebe-se que esse período histórico coincide com a segunda metade da onda longa da quarta revolução tecnológica. Ademais, mostrar-se-á que as duas fases características do período de desacoplamento do paradigma tecnoeconômico em tela - sinergia e maturidade - guardam estreita relação com os acontecimentos vivenciados pela economia brasileira no período que vai da década de 1950 até o final dos anos 1970.

Na segunda metade da década de 1950, os governos Café Filho e, em especial, $\mathrm{JK}$, foram simpáticos a uma estratégia de internacionalização do mercado interno nacional, atrelando a economia nacional ao movimento expansivo do capital internacional. No período do Plano de Metas (1956-1961) houve uma entrada abundante de IED em comparação com os anos anteriores. Pode-se dizer que a lógica

\footnotetext{
${ }^{3}$ Vale novamente ressaltar que, apesar da elevação da liquidez nas fases de frenesi e de maturidade, os fluxos de capital são qualitativamente diferentes nesses dois momentos. Na maturidade, conforme enfatizado anteriormente, o capital financeiro tende a estar mais vinculado à produção, à busca de novos mercados e à expansão do paradigma maduro. Durante o frenesi, os fluxos de capital são muito mais especulativos e estritamente financeiros. Por isso, a vulnerabilidade externa de uma economia periférica tende a ser reduzida somente nas fases de maturidade de um paradigma tecnoeconômico, quando tanto o capital financeiro quanto o capital produtivo dos países centrais buscam mercados distantes para exatamente alargar o ciclo de vida da revolução tecnológica. Essa dinâmica do período de maturidade pode fazer com que a restrição externa de um país periférico seja substancialmente reduzida, pois diminui seu coeficiente de importação em razão da internacionalização do mercado interno, e o capital financeiro está mais disposto a financiar projetos para o desenvolvimento. $\mathrm{Na}$ fase de frenesi, a economia periférica tende a ver-se em debilidade em função da elevação do seu coeficiente de importações que a revolução tecnológica, em marcha nos países avançados, acarretou. Por mais que se eleve a liquidez internacional nesse período, os fluxos de capital são caracterizados por um comportamento curto-prazista, o que acaba por exacerbar ainda mais a vulnerabilidade do país periférico.
} 
da estratégia nacional residia em construir um cenário interno atrelado ao movimento de expansão das empresas multinacionais. Assim, a estratégia consistia na elaboração de políticas de incentivo e atração de recursos externos, sobretudo na forma de investimentos estrangeiros diretos (IED), como aproveitamento da expansão capitalista dos países desenvolvidos.

A intensificação do processo de industrialização nacional, num curto espaço de tempo, foi possível porque a estratégia de desenvolvimento brasileira vinculou-se ao movimento de internacionalização de capital de forma bastante estreita. A influência de grandes conglomerados internacionais sobre a dinâmica da economia brasileira era destacada, já na década de 1960. Também se pode afirmar que o mercado interno brasileiro tornou-se o mais internacionalizado da América Latina ao findar o Plano de Metas.

A base tecnológica dinâmica de crescimento das principais economias núcleo da quarta revolução industrial caracterizava-se pela sua ênfase nos complexos metalomecânico-químico. A participação dos gêneros industriais constituintes dos complexos metalomecânico-químico apresentou aumento significativo no valor da transformação industrial a partir da consolidação do Plano de Metas, passando de $25 \%$, em 1939, para 43\% em 1959. Nesse sentido, percebe-se que o emparelhamento tecnológico (catching up) brasileiro ao paradigma em vigor é concreto já na década de 1960. A continuidade da mudança estrutural deu-se até 1980, pois os gêneros industriais constituintes dos complexos metalomecânico-químico representavam $58 \%$ do valor da transformação industrial da indústria de transformação (ver Versiani; Suzigan, 1990).

De acordo com o argumento desenvolvido até aqui, se a mudança industrial para setores dinâmicos ocorresse por meio de recursos externos, especialmente sob a forma de IED, seria de esperar que a participação do capital internacional fosse predominante exatamente nesses setores. Segundo dados apresentados por Serra (1982, p. 19), em 1970, entre as empresas líderes, as multinacionais dominavam a produção de bens de consumo ( $85 \%$ das vendas) e participavam majoritariamente na produção de bens de capital (57\% das vendas). Para Serra (1982, p. 18), o "salto da indústria brasileira na direção dos ramos manufatureiros 'pesados' de bens de produção e de consumo duráveis é inseparável da penetração das empresas transnacionais no setor".

Nesse sentido, tudo indica que, da segunda metade dos anos 1950 até o final da década de 1970, o ingresso de capital estrangeiro influiu no desempenho da economia brasileira de forma positiva, principalmente ao internalizar os setores-chave da quarta revolução tecnológica. A forte presença do capital estrangeiro na estrutura industrial brasileira possibilitou o catching up nacional, ou o emparelhamento tecnológico, ao quarto paradigma tecnoeconômico. A estrutura industrial brasileira tinha alcançado, em 1980, um alto grau de integração intersetorial e de diversificação da produção. Os complexos químico e metalomecânico (constituintes dos setores de bens de capital, bens de consumo duráveis e do setor automobilístico), que representavam 47,5\% da produção industrial total em 1970, foram, em 1980, responsáveis por $58,8 \%$ do produto total da indústria. A estru- 
tura industrial resultante não era significativamente diferente da maior parte das economias da Organização para a Cooperação e Desenvolvimento Econômico (OCDE). Em 1980, as três economias mais desenvolvidas tinham, aproximadamente, dois terços da sua produção industrial originada desses setores: $64,4 \%$, no caso dos Estados Unodos; 64,5\%, no caso Japão; e 69,8\% no caso da Alemanha Ocidental (Cassiolato, 2001).

A maturidade é a última fase de uma onda longa de desenvolvimento, e faz-se relevante compreender sua dinâmica para o entendimento do processo de industrialização brasileiro. Nesta fase os países núcleo passam a exportar o paradigma tecnológico em direção à periferia. Como as trajetórias tecnológicas das indústrias núcleo do paradigma, após meio século de evolução, cercam-se de seu esgotamento, a taxa de investimento tende a diminuir nos países centrais. Por isso, o "dinheiro ocioso" não para de crescer na fase de maturidade, segundo Perez (2004), pois, ao final da revolução tecnológica, há um potencial inercial de acumulação de riqueza construído a partir do poder monopolista das grandes empresas.

O surgimento do mercado de eurodólares é reflexo desse processo, bem como as maiores concessões de empréstimos à periferia por parte dos bancos comerciais europeus nessa época foram consequência da queda de dinamismo econômico das economias centrais. Assim, não só capital produtivo migrou para o Brasil durante o final da quarta onda longa. A fase de maturidade também anunciou o aparecimento de uma "janela de liquidez" internacional para economias periféricas. Nessa fase, o capital financeiro se fez menos exigente em suas concessões de crédito. Por isso, a escassez crônica de divisas e a restrição externa da economia brasileira foram amenizadas nessa época em razão da disposição do sistema financeiro internacional em estender empréstimos e aceitar financiar projetos sujeitos a uma vulnerabilidade maior. A crise da dívida latino-americana dos anos 1980 iniciou seu crescimento com empréstimos para o desenvolvimento em meados de 1960, e se intensificou com a pletora de petrodólares dos anos 1970, exatamente na fase de maturidade da quarta revolução tecnológica.

Nesses termos, o período do "milagre brasileiro" e do II PND foram potencializados pelo "dinheiro ocioso" (euromercados, petrodólares), que recorrentemente há nas fases de maturidade das revoluções tecnológicas. A partir do final da década de 1960, essa oferta de liquidez supriu a incapacidade do sistema financeiro nacional em ofertar financiamento de longo prazo. Nas devidas proporções, finalizou-se, no Brasil, a montagem de uma estrutura industrial análoga à (então) existente nas economias desenvolvidas. Os investimentos estrangeiros ampliavam-se em uma fase de relativa estabilidade tecnológica mundial, provocando internamente mudança industrial para estágios mais avançados, mas, ao mesmo tempo, diminuindo a necessidade por esforços nacionais para a internalização de um núcleo endógeno de desenvolvimento tecnológico. Enquanto os países precursores e dinâmicos da revolução já se encontravam "lentos" em razão do seu tamanho e, por isso, buscavam mercados externos para alargar o ciclo de vida da revolução tecnológica já em maturidade, os recém-incorporados avançavam aceleradamente por intermédio de "milagres" tardios em direção às tecnologias dinâmicas da quarta 
onda longa. Isso pode ser entendido como uma questão de peso e ritmo relativo. De fundamental relevância é compreender que as mudanças estruturais que vinham ocorrendo na estrutura industrial brasileira desde meados dos anos 1950 deram-se, sobretudo, com aportes maciços de capitais externos. Por essa razão, mesmo após a aparente convergência tecnológica, o processo de transformação industrial brasileiro continuaria subordinado ao ingresso de recursos externos.

A década de 1980 anuncia a chegada de um novo período de crescente divergência tecnológica mundial, anulando alguns avanços alcançados por muitos países periféricos no período anterior, em especial, pelo Brasil, como se verá. Enquanto alguns países periféricos ainda estavam experimentando milagres tardios de sinergia com o paradigma vigente, outros já estavam avançando na fase de turbulências e tensões provocadas pela seguinte revolução tecnológica. ${ }^{4}$

Com o esgotamento das possibilidades de inversão nos complexos metalomecânico-químico já nos anos 1970, os países centrais buscaram se reestruturar tecnológica e produtivamente. As indústrias núcleo do paradigma anterior logo foram deslocadas do topo da matriz industrial, bem como deixaram de ser responsáveis pela dinâmica de crescimento das economias centrais. Segundo Laplane (1992), a partir dos anos 1980 o eixo dinâmico da atividade industrial nos países desenvolvidos deixou de ser o setor automobilístico (característico do paradigma metalo-mecânico-químico) para ser o Complexo Eletrônico (paradigma microeletrônico). Também o peso do complexo eletrônico nas estruturas industriais dos países desenvolvidos passou a ser crescente, chegando a superar a participação do complexo automobilístico na estrutura industrial, carro-chefe da dinâmica de crescimento da quarta onda longa.

Segundo Cassiolato (2001), a partir do início dos anos 1980 e ao longo dos anos 1990 nota-se que a estrutura industrial brasileira evoluiu de maneira extremamente diversa daquela ocorrida naqueles países que melhor se adaptaram ao novo paradigma microeletrônico, tanto em relação aos desenvolvidos quanto aos em desenvolvimento. Houve um movimento de estagnação da participação dos setores industriais mais dinâmicos da nova revolução tecnológica na estrutura industrial brasileira. O setor de material elétrico, eletrônico e de comunicações, que representava $7,12 \%$ da indústria de transformação em 1980, passa a representar apenas $6,56 \%$ em 1999. O atraso da economia brasileira em direção a setores típicos do paradigma microeletrônico é seguido por um aumento significativo da participação das indústrias processadoras de recursos naturais no produto total da indústria. ${ }^{5}$ Uma avaliação geral indica que cada vez mais a indústria brasileira se

\footnotetext{
${ }^{4} \mathrm{O}$ período de coexistência de dois paradigmas constitui uma bifurcação na estrutura de produção, separando os setores novos e dinâmicos dos velhos e obsoletos. É também um período de bifurcação, quando os países centrais começam a experimentar verdadeiros problemas tanto econômicos como sociais, enquanto outros países, que estão em processo de persecução (catching $u p$ ), alcançam seu máximo esplendor.

${ }^{5}$ Segundo Feijó e Carvalho (2008), em 2006 mais da metade da produção industrial (50,3\%) se
} 
especializa na produção de commodities, enquanto setores importantes do ponto de vista tecnológico apenas mantêm espaço (Feijó e Carvalho, 2008) que, diga-se de passagem, é muito reduzido.

Aliado à reduzida participação dos setores emblemáticos do paradigma microeletrônico e aos elevados ganhos de participação dos recursos naturais na estrutura industrial brasileira, outro fenômeno significativo tem revelado a trajetória singular de baixo dinamismo da economia brasileira nas últimas décadas. Trata-se da forte queda de participação da indústria de transformação no PIB, sendo em parte explicada pela própria reespecialização da economia brasileira em setores intensivos em recursos naturais, os quais retiram o dinamismo da indústria e da totalidade da economia.

Em 1955, sua participação era de $21 \%$ e, ao final do Plano de Metas, em 1961, acercava-se de $28 \%$. Ao final do período do "milagre", em 1973, era de $33 \%$ e, após a finalização do II PND, atingiu seu pico, próximo dos 36\% do PIB em 1985. Ao longo desse período, a indústria de transformação aumentou sua participação relativa em $71 \%$ no PIB. A partir daí, começa a perder, de forma sustentada, participação relativa no PIB brasileiro. Em 1990, esta era de 26,5\%, registrando um decréscimo de praticamente dez pontos percentuais em apenas cinco anos. Em 1998, a participação da indústria de transformação atingiu o valor de $15,7 \%$ do PIB, encontrando-se um pouco acima desse patamar nos dias atuais. ${ }^{6}$ Assim, nas duas últimas décadas, perdeu mais de 50\% de participação relativa no PIB. Em 1955, mesmo antes do Plano de Metas, ela detinha uma participação relativa $25 \%$ superior à do ano 2000! A partir dos anos 1980, a evolução da estrutura industrial brasileira apresentou um retrocesso em relação ao seu desempenho anterior. Em vez da continuidade do catching up, um processo de falling behind marcou a trajetória da indústria brasileira nas últimas décadas.

Palma (2005) discute o referido fenômeno sugerindo que a ruptura com o modelo de substituição de importações para um movimento de liberalização comercial e financeira teria acarretado não somente uma perda relativa e precoce de participação da indústria no PIB, mas também um retorno ao padrão de especialização internacional, baseado em recursos naturais. A partir dos anos 1990, as vantagens comparativas naturais (ricardianas) explicariam grande parte do sucesso do agribusiness brasileiro pós-liberalização econômica. A posição de Bresser-Pereira (2007) é similar à de Palma (2005). Segundo Bresser-Pereira, a taxa de câmbio valorizada, ao incentivar as importações, é fonte de desindustrialização prematura. Assim, a partir da década de 1990 a perda de importância da indústria é, via de regra, associada ao aprofundamento do processo de abertura econômica e à valorização da taxa de câmbio.

Que outros fatores poderiam ter atuado para a manifestação da crescente di-

concentrava em apenas quatro setores, sendo que três estavam diretamente associados ao processamento de recursos naturais.

${ }^{6}$ Fonte: IBGE/SCN 2000 anual. Disponível em www.ipeadata.gov.br. 
vergência de desenvolvimento do parque industrial nacional em relação aos países avançados e em desenvolvimento dinâmico ou para seu falling behind? A questão pode ser mais bem elucidada ao se ter presente o sucesso do período anterior, de catching up, o qual foi fundamentalmente beneficiado pelo movimento de internacionalização do capital, na forma de investimentos diretos e empréstimos ao desenvolvimento, e que esse movimento fazia parte de uma dinâmica particular da fase final da quarta revolução tecnológica.

Como durante o catching up brasileiro, no período 1955-1980, a capacidade de aprendizado nacional não foi estimulada para assegurar relativa autonomia tecnológica, o ingresso do país na nova revolução tecnológica dependeria, sobretudo, de fluxos de investimentos diretos engajados em um processo de revitalização da indústria eletromecânica e de bens de capital, tal qual estava em curso nos países centrais. Ocorre que entre os países em desenvolvimento, o Brasil, enquanto receptor de investimentos externos, caiu da primeira, em 1980, para a décima quarta posição em 1993. O Brasil, que recebia em média $25 \%$ de todos os fluxos de IED ao longo dos anos 1970 passou, em pouco tempo, a uma posição quase que insignificante (Cassiolato e Lastres, 2005). ${ }^{7}$

Até a primeira metade da década de 1980 os fluxos estrangeiros direcionavam-se, em sua grande maioria, para a indústria, chegando próximo de $80 \%$ do total. A partir de meados dessa década, o Brasil recebe fluxos de IED para o setor industrial de forma decrescente. É interessante notar que a trajetória dos fluxos de investimentos estrangeiros para o setor industrial é similar ao movimento de participação da indústria de transformação no PIB indicado anteriormente: apresenta uma ligeira queda em meados dos anos 1980, perde participação de forma abrupta na segunda metade da década de 1990 e recupera-se um pouco na primeira metade da década de 2000.

A partir de meados dos anos 1990, observa-se nítida mudança nos fluxos de IED, e o setor de serviços passa a ser o principal canal de atração, em detrimento do setor industrial. $\mathrm{O}$ processo de fusões e aquisições aliado à onda de privatizações explica a reversão de tendência e a inaptidão do IED para a criação de nova capacidade produtiva. Assim, apesar do retorno e do abundante fluxo de capitais internacionais nos anos 1990, estes não impactam o crescimento das taxas de investimento. No entanto, poder-se-ia questionar se os IEDs do período 1980-1995 destinados ao setor industrial, portanto antes da predominância para o setor de

\footnotetext{
${ }^{7}$ Segundo dados de Cassiolato e Lastres (2005), a industrialização baseada em substituição de importações, ao estimular a entrada de capital estrangeiro, fez o Brasil se tornar um dos destinos mais importantes para o investimento direto estrangeiro até o início dos anos 1980. Segundo esses autores, o Brasil apresentava reduzidas restrições relativas a políticas relacionadas a capital, investimento e tecnologias estrangeiras, tornando-se o país em desenvolvimento mais atraente para IED nos anos 1960 e 1970. Em 1977, por exemplo, o país recebeu $15 \%$ de todo o investimento estrangeiro das nações em desenvolvimento e, em 1980, o país tinha o maior estoque de investimento estrangeiro entre os países em desenvolvimento (e o sétimo maior no mundo). Dessa forma, a partir de 1955 o Brasil adota uma das políticas mais atraentes ao investimento estrangeiro entre os países em desenvolvimento.
} 
serviços, poderiam ser característicos do novo paradigma tecnoeconômico e provocar um processo de reestruturação industrial. O Gráfico 2 mostra que isso não ocorreu, indicando que a entrada de IED para a indústria de transformação brasileira concentrou-se em setores característicos do paradigma metalomecânico-químico e commodities industriais. Durante o período em consideração, em todos os anos esses setores industriais representaram mais de $70 \%$ do total do ingresso de IED.
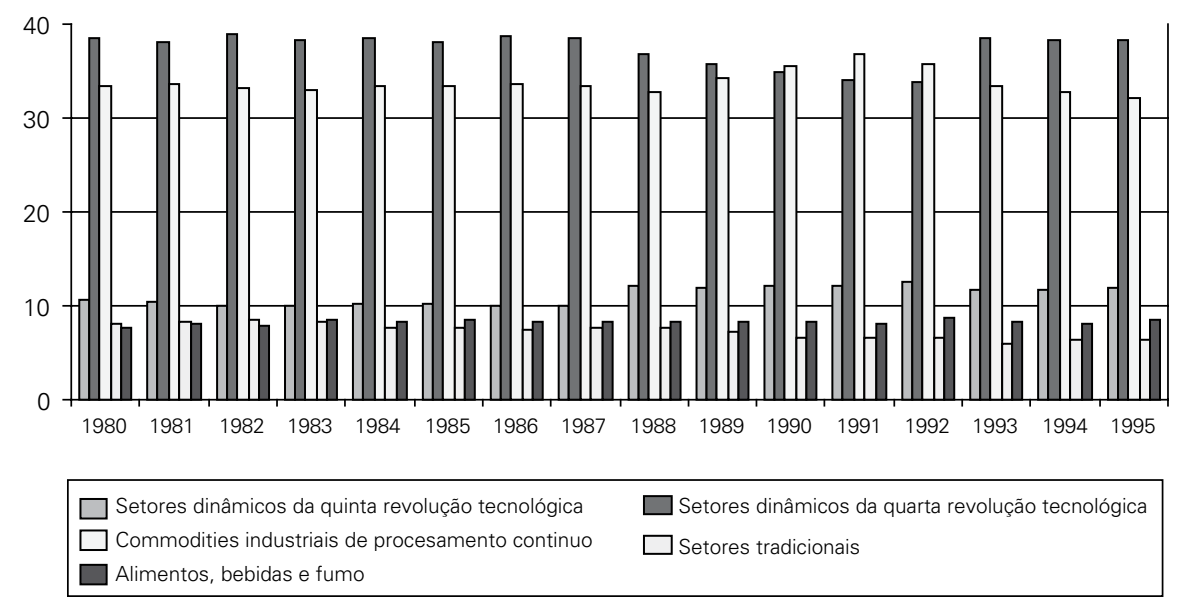

Fonte: Elaborado a partir de dados do Banco Central do Brasil (2008). ${ }^{8}$

A entrada de IED nos setores dinâmicos do paradigma microeletrônico, do Complexo Eletrônico, foi muito reduzida, evidenciando a debilidade da estratégia de mudança industrial arquitetada nos anos 1990. Assim, os setores dinâmicos do paradigma de crescimento mundial não se difundiram para o Brasil na forma de investimentos estrangeiros diretos como no passado. Além disso, continuaram os fluxos que especializaram cada vez mais a estrutura industrial no paradigma anterior, metalomecânico-químico, e em recursos naturais. Portanto, o padrão de investimento direto externo, no período 1980-1995, e a extrema dependência por transferências tecnológicas, característica da estratégia de desenvolvimento do período anterior a 1980, exerceu influência para a debilidade do processo de mudança industrial no período posterior.

O novo atrelamento da economia brasileira à dinâmica internacional, ocorrido na década de 1990, recebeu fluxos de investimentos estrangeiros característicos da fase de frenesi. As décadas de 1980 e 1990 foram caracterizadas por dois fenômenos contraditórios. De um lado, floresceu plenamente a revolução tecno-

\footnotetext{
${ }^{8}$ A organização setorial é baseada em Curado (1997).
} 
lógica nos países avançados, instalando-se a infraestrutura e estabelecendo-se claramente o novo paradigma tecnoeconômico. Em virtude disso, em certo número de países houve setores crescendo rapidamente e difundindo um enorme potencial de transformação e geração de riqueza, com o apoio do capital financeiro. Mesmo existindo obstáculos e vazios regulatórios e institucionais, as novas indústrias e suas empresas tomaram a dianteira das que antes foram os motores do crescimento. De outro lado, as indústrias de muitos países que não ingressaram — ou não puderam ingressar - na trajetória da modernização se deterioraram visivelmente e entraram em um círculo vicioso de baixo crescimento e escassez de fundos. Em razão de sua extrema dependência tecnológica, restrição externa e da "necessidade" de recursos externos, esses países viram-se atrasados tecnologicamente e compelidos a mudanças institucionais para a atração de investimentos estrangeiros. ${ }^{9}$

O retorno da integração da economia brasileira aos fluxos de capitais internacionais, nos anos 1990, pôde desfrutar do que os países avançados tinham de mais abundante em suas economias nesse período: a liquidez financeira e o seu caráter curto-prazista. Logicamente que a estratégia de um "segundo catching up" nacional, baseada novamente no aporte de poupança externa, foi bastante limitada.

\section{LOCK-IN E PATH DEPENDENCE NA ECONOMIA BRASILEIRA: A VULNERABILIDADE DO PADRÃO DE CATCHING-UP BASEADO NA INTERNACIONALIZAÇÃO DO MERCADO INTERNO}

Um dos pressupostos da abordagem evolucionista refere-se à questão de que determinadas escolhas e eventos históricos, por mais distantes e remotos, podem continuar a afetar o desempenho econômico presente. Trata-se do fenômeno de path dependence, segundo o qual a memória do sistema econômico, ou sua experiência prévia, condiciona para que a tomada de decisões no presente seja coerente

\footnotetext{
${ }^{9}$ Segundo Bresser-Pereira (2007), a ortodoxia convencional, ou seja, o conjunto de diagnósticos e recomendações originadas de Washington, manifestou-se, a partir dos anos 1980, pelo que ficou conhecido como o Consenso de Washington. Teve início um amplo processo de liberalização econômica e redução da regulação aos investimentos diretos estrangeiros, o qual, segundo o "consenso", provocaria uma reestruturação do parque industrial brasileiro para estágios mais avançados. Foram eliminadas diversas restrições ao ingresso do capital estrangeiro. Entre 1990 e 1992, as principais foram: a) início da concessão de financiamentos do BNDES, a partir de 1991, a empresas multinacionais (EMNs); b) redução do poder regulatório do Instituto Nacional da Propriedade Industrial (INPI), responsável pela aprovação de acordos de transferência de tecnologia; c) fim da Lei de Informática em 1992; d) autorização, em 1991, para que as EMNs passem a usar lucros financeiros para constituir aumento de capital registrado; e) permissão, em 1991, para pagamento de royalties das EMNs para suas matrizes; f) redução do Imposto de Renda sobre remessas; e g) autorização de remessas de dividendos associadas a capital ainda em via de registro no Banco Central do Brasil. A partir de 1995, tem início nova onda de medidas favoráveis ao investimento estrangeiro. Destacam-se a eliminação da separação constitucional entre empresas nacionais e estrangeiras, a eliminação ou redução de restrições a investimentos externos nos setores de petróleo, extrativa mineral, bancos e seguradoras, navegação de cabotagem e telecomunicações e a nova lei de propriedade industrial. (cf. Nonnenberg, 2003, p. 31.)
} 
com as mudanças efetuadas no passado. Nesse sentido, pode-se depreender que as trajetórias de desenvolvimento de países são dependentes das formas de aprendizado tecnológico e de políticas econômicas do passado. Por isso, as possibilidades tecnológicas emergentes em cada momento são determinadas por escolhas passadas e irreversíveis e, em função da cumulatividade, estão sujeitas ao fenômeno de lock in (aprisionamento).

A opção pela estratégia de catching up ancorada na internacionalização produtiva, no período 1955-1980, obteve elevado êxito no que concerne à convergência nacional ao paradigma tecnoeconômico da quarta revolução tecnológica. O peso cada vez maior das empresas multinacionais na dinâmica econômica nacional internalizou indústrias emblemáticas do paradigma tecnológico em via de maturação. Essa conjuntura evidentemente não seria perpétua. O centro desenvolvido buscou se diferenciar da periferia, avançando em uma nova revolução tecnológica, e o Brasil engajou-se nessa nova fase do capitalismo internacional, desnudando suas limitações técnicas e financeiras anteriormente latentes. O Brasil ingressou em uma relativa estagnação de suas taxas de crescimento, restrição externa, desindustrialização precoce e atraso tecnológico, ou seja, em um processo de falling behind..$^{10}$

O Gráfico 3 ilustra uma relação extremamente relevante para o entendimento da dinâmica de longo prazo da economia brasileira. No período 1955-1980, a relativa facilidade em solucionar o problema da restrição externa deve ser levada em consideração ao se analisar seu desempenho. A partir de 1955, as entradas de capitais externos (IED e empréstimos) intensificaram-se e financiaram sucessivos déficits em transações correntes. $\mathrm{O}$ transbordamento de muitas indústrias núcleo do paradigma metalomecânico-químico e a existência de "dinheiro ocioso" nas economias avançadas disponibilizaram recursos externos que contribuíam não somente para a aceleração da taxa de investimento doméstica, mas também sustentaram a aceleração da demanda por importações. Assim, essa estratégia de crescimento foi amplamente eficaz ao promover crescimento com transformação industrial.

\footnotetext{
${ }^{10}$ Arend (2009) discute a instituição da estratégia brasileira do período pós-1955 e seus efeitos debilitantes no longo prazo, denominando-a de "desenvolvimentista internacionalista", em contraposição à estratégia anterior, do segundo governo Vargas, "nacional-desenvolvimentista”.
} 


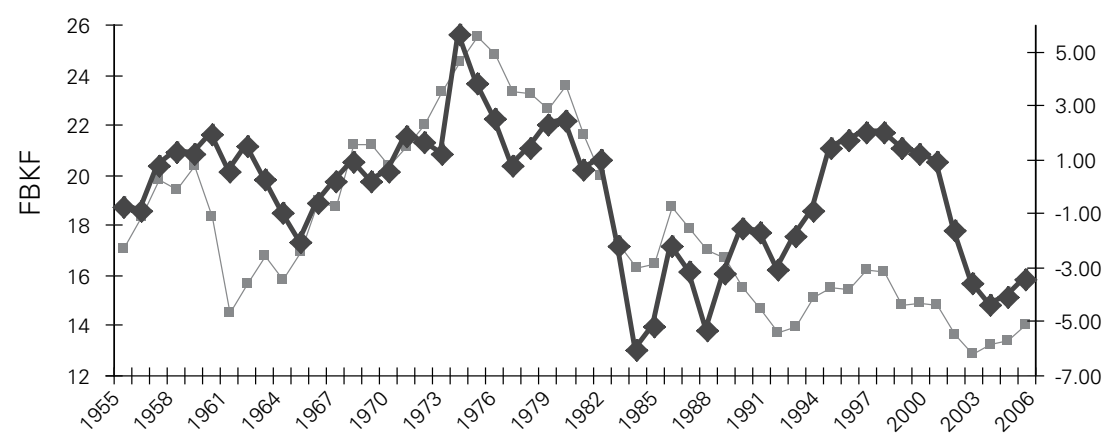

$$
\longrightarrow \text { FBCF } \longrightarrow \text { Poupança externa }
$$

Fonte: Elaborado a partir de dados do Banco Central do Brasil (2008) e do Instituto de Pesquisa Econômica Aplicada (2008).

Notas:

1) FBKF como proporção percentual do PIB, a preços constantes de 1980.

2) Poupança externa real (PER) obtida pelo cálculo de médias simples, em percentual do PIB. O PIB, em US\$, foi apurado com base na taxa de câmbio média do ano, com base no IBGE/SCN (apud INSTITUTO DE PESQUISA ECONÔMICA APLICADA, 2008). Sobre a metodologia do cálculo da PER, ver Silva (2006). ${ }^{11}$

Percebe-se, pela evolução da taxa de FBKF, o esforço de ampliação e de diversificação da economia brasileira até o final da década de 1970. Também, nota-se que, à medida que a FBKF assumia maior participação no PIB, aumentava a requisição de poupança externa para admitir a expansão na capacidade produtiva da economia: a intensificação nas taxas de crescimento dera-se com absorção de pou-

${ }^{11}$ Costuma-se designar de poupança externa o resultado líquido das transações correntes de um país. Em linhas gerais, o valor da PER equivale ao resultado líquido da Balança de Transações Correntes subtraído os pagamentos de renda ao exterior. A vantagem desse indicador é que, em vez de simplesmente indicar o saldo líquido das transações correntes, ele pode indicar o volume de divisas realmente utilizadas para aquisição de ativos reais. Segundo A. X. Silva (2006, pp. 73-74), o indicador da Poupança Externa Real é obtido a partir do seguinte procedimento: em primeiro lugar, obtém-se o indicador referente à Oferta Total de Divisas (OTD), a partir da soma de duas contas do balanço de pagamentos: (i) o resultado líquido das transações correntes (o déficit) e (ii) o resultado líquido das transferências unilaterais, adicionadas de uma terceira variável: (iii) o resultado global do BP. Esse indicador aponta o total de "crédito" oferecido pelo mundo ao país a cada ano, indicando os limites virtuais para o excesso de absorção doméstica que serão sancionados pela comunidade econômica internacional. A partir do indicador OTD, obtém-se o indicador das Divisas Utilizadas (DU), por meio da subtração do resultado global do balanço de pagamentos da OTD. Isso se torna necessário porque tal variável representa o excesso de recursos externos entrantes que é destinado à composição das reservas internacionais e não tem, portanto, efeito direto sobre o nível de atividade econômica corrente. Por fim, obtém-se a Poupança Externa Real (PER) pela subtração dos gastos associados ao pagamento das rendas do indicador DU. Ao retirar os gastos com o pagamento de rendas ao exterior do resultado líquido das transações correntes, busca-se apurar o volume de divisas requerido para a sustentação das decisões de gasto correntes. 
pança externa, e esta contribuía significativamente para o processo de industrialização. Os recursos externos não somente financiaram altas taxas de crescimento econômico, mas também ajudaram a promover o catching up, pois o capital estrangeiro, além de financiar o crescimento, instalou-se também nos setores dinâmicos.

O período de "despoupança" externa (transferência de recursos reais ao exterior) da década de 1980 corrobora as afirmativas do parágrafo anterior. Há uma forte coincidência entre a queda nas taxas de FBKF e de crescimento econômico, quando interrompe a trajetória de absorção de recursos externos, além do começo do processo de desindustrialização nacional. Os reduzidos fluxos de investimentos estrangeiros diretos e a reduzida transferência de tecnologia no estado da arte, por essa via, anunciaram o início do processo de "desconexão forçada". De 1980 até meados da década de 1990, o Brasil perdeu o posto de economia em desenvolvimento que mais recebia transferências tecnológicas. Aliado a isso, o reduzido volume de investimentos externos direcionou-se apenas para setores já instalados da matriz industrial e para segmentos industriais baseados na transformação de recursos naturais, encerrando o período de intensa mudança estrutural que vinha ocorrendo de 1955 até 1980.

As baixas taxas de FBKF, nos anos 1980, associam-se do baixo nível do investimento do período. O ajuste nas economias avançadas, já na década de 1970, redirecionou o investimento das empresas multinacionais para mercados prioritários dos países desenvolvidos, reduzindo o nível de investimento no Brasil. Portanto, a dinâmica da quinta revolução tecnológica afetou a estrutura de investimento brasileira, que vinha tendo como um dos seus pilares os investimentos estrangeiros. Isso dificultou ao país ingressar na quinta revolução tecnológica durante a década de 1980, pois a anterior estrutura de investimento foi desarticulada mediante a diminuição da participação do capital privado internacional, direcionando o Brasil para uma defasagem tecnológica em relação ao resto do mundo, evidente já no início dos anos 1990. Essa dinâmica revelou que a estrutura industrial brasileira não foi capaz, sem o recurso do capital estrangeiro, de ingressar na quinta revolução tecnológica.

A partir de meados dos anos 1990, assiste-se a absorção de elevadas somas de poupança externa. Entretanto, seu impacto nas taxas de FBKF é reduzido, a sugerir que os recursos disponibilizados pela comunidade internacional não guardavam relação com o investimento doméstico. Dessa forma, a última década do século XX revela que houve uma ruptura na relação histórica entre a taxa de FBKF e a taxa de poupança externa. Na seção anterior, procurou-se mostrar a debilidade da estratégia de crescimento com poupança externa em um período de dominância financeira. Isso ficou explicitado quando se enfatizou que os investimentos externos, na década de 1990, assumiram um caráter eminentemente financeiro, típico das fases de frenesi da revolução tecnológica, e não produziram aceleração nas taxas de investimento da economia brasileira.

Bresser-Pereira (2007) interpreta a conjuntura de baixo nível de investimento dos anos 1990 a partir de sua tese da "substituição de poupanças". Para ele, o influxo de recursos externos, ao acarretar apreciação cambial, eleva artificialmente os salários reais e o consumo, diminuindo a taxa poupança interna. Para esse autor, o influxo de poupança externa somente impacta de forma positiva na taxa doméstica de investi- 
mentos em momentos excepcionais, quando grandes oportunidades de investimento persuadem a classe média profissional e os capitalistas a consumir relativamente menos. A tese de Bresser-Pereira sobre o fenômeno da complementaridade e substituição entre as poupanças interna e externa foi construída a partir de evidências do período pós-1990. Mas, ao se alargar o período de análise para os últimos 50 anos, percebe-se que o caso brasileiro apresenta uma dinâmica interessante.

O Gráfico 4 mostra a estreita evolução complementar entre as taxas de poupança interna e externa de 1955 até o final da década de 1970. A partir daí, as taxas de poupança interna e externa apresentam trajetórias visivelmente contrárias.

Percebe-se o fenômeno da "substituição de poupanças" desde meados da década de 1980. A relação complementar entre as taxas de poupança no período 1955-1980 sugere, seguindo as indicações de Bresser-Pereira (2007), que o país apresentava extraordinárias perspectivas de lucro, e os empresários, elevada propensão a investir. De fato, pela abordagem neoschumpeteriana, ficou claro que essa circunstância excepcional foi permitida pela estratégia de catching up baseada na internacionalização do mercado interno, em consonância com o período de maturidade do paradigma tecnoeconômico da quarta revolução tecnológica. $\mathrm{O}$ amplo ingresso de investimento estrangeiro direto e a estabilidade tecnológica, aliados ao "dinheiro ocioso", presente nas economias avançadas e que propiciou uma "janela de liquidez" para uma gama de projetos financiados pelo Estado, impactaram positivamente para o catching up brasileiro, elevando a propensão a investir e as perspectivas futuras de lucro na economia.

\section{Gráfico 4: Evolução da Absorção de Poupança Externa}

e da Taxa de Poupança Interna no Período 1955-2006

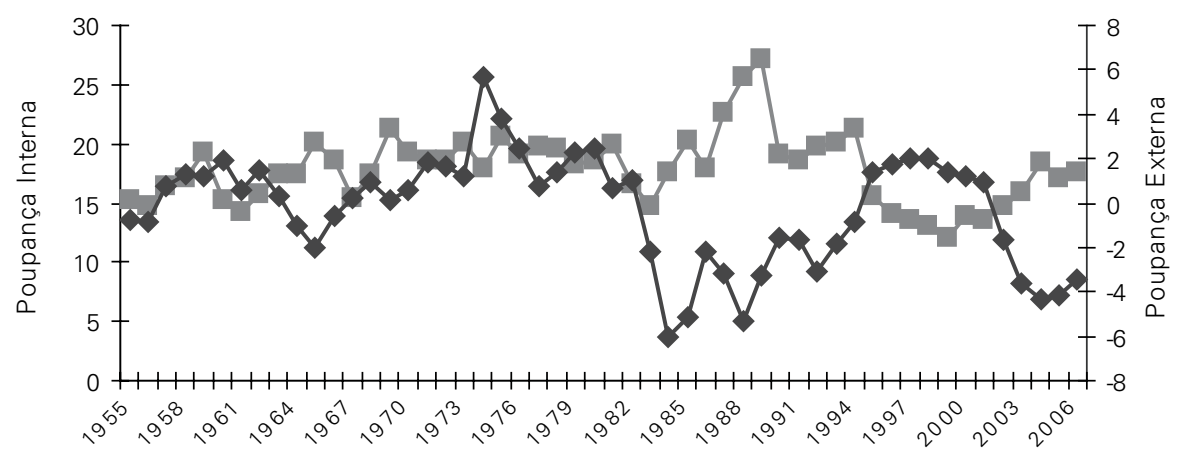

— Poupança interna

Fonte: Elaborado a partir de dados do Banco Central do Brasil (2008) e do IBGE/SCN (apud INSTITUTO DE PESQUISA ECONÔMICA APLICADA, 2008).

Notas:

1) Poupança nacional bruta como proporção percentual do PIB.

2) Poupança externa real (PER) obtida pelo cálculo de médias simples, em percentual do PIB. O PIB, em US\$, foi apurado com base na taxa de câmbio média do ano, com base no IBGE/SCN (apud INSTITUTO DE PESQUISA ECONÔMICA APLICADA, 2008). Sobre a metodologia do cálculo da PER, ver Silva, 2006. 
Nos anos 1980, a taxa de poupança interna se apresentou extremamente elevada, alcançado níveis, em alguns anos, superiores aos de períodos de intenso crescimento, como do Plano de Metas, "milagre” e II PND. Entretanto, as elevadas taxas de poupança interna não foram suficientes para alavancar a taxa de FBKF e o crescimento econômico, evidenciando a baixa produtividade dos investimentos domésticos. É nessa década que se interrompe a dinâmica complementar entre as poupanças interna e externa que vinha ocorrendo desde 1955. Nota-se, portanto, que o movimento de despoupança externa impactou de forma negativa na dinâmica econômica nacional. Mostrou-se que, a partir dessa década, com a quinta revolução tecnológica em marcha nos países avançados, o Brasil deparou-se com a interrupção de seus canais tradicionais de financiamento do crescimento.

Nos anos 1990, assiste-se à absorção de poupança externa em níveis equivalentes aos dos períodos do Plano de Metas e do "milagre", enquanto as taxas de poupança interna e de FBKF reduziam-se consideravelmente a seus menores patamares dos últimos 50 anos. Ou seja, a dinâmica da substituição de poupanças, e seus efeitos negativos sobre as taxas de FBKF e de crescimento econômico, é um fenômeno recorrente nos últimos 25 anos.

No passado, ao se optar por uma estratégia de desenvolvimento que proporcionava retornos crescentes imediatos, criou-se uma institucionalidade que tendeu a concentrar esforços cada vez mais nesse tipo de solução, o fenômeno lock-in. A busca para a solução do baixo dinamismo econômico da década de 1980 concentrou esforços para a atração do principal agente responsável pela dinâmica anterior. A estratégia de desenvolvimento ficou lock-in (aprisionada) no internacionalismo. A história, todavia, não se repetiu. Afinal, poder-se-ia afirmar, cum grano salis, que a periferia deixaria de ser periferia se a estratégia de crescimento com poupança externa acarretasse crescimento com mudança estrutural no longo prazo, ad infinitum.

\section{CONCLUSÃO}

A busca por convergência tecnológica por parte de países retardatários, pelos esforços que põem em movimento um processo autônomo de "superação do atraso" por meio de empresas locais, supõe uma trajetória de desenvolvimento menos vulnerável às idas e vindas do capital internacional no longo prazo. Não parece ter sido esse o caso do relativo emparelhamento tecnológico realizado pelo Brasil no período 1955-1980. A partir do Plano de Metas, foram os investimentos de empresas multinacionais o principal veículo de difusão internacional de tecnologia. Procurou-se demonstrar que essa estratégia de desenvolvimento é vulnerável, pois não garante uma endogenia técnica. Um processo autônomo de superação do atraso é outra maneira de expressar a necessidade de uma estratégia nacional-desenvolvimentista (Sicsú, Paula e Michel, 2007).

O recurso analítico ao aproach neoschumpeteriano auxilia para mostrar que o período 1955-1980 tratava-se de um momento particular, de maturação das 
tecnologias da quarta revolução, de saturação dos mercados e queda da produtividade nas economias avançadas. Com a irrupção do novo paradigma tecnoeconômico, pode-se perceber que os fluxos de capitais internacionais assumiram uma dimensão muito mais financeira e desvinculada da economia real, exacerbando a vulnerabilidade de países engajados em crescer com poupança externa. Desde 1980, os investimentos estrangeiros diretos, apesar de abundantes em alguns momentos, não internalizaram, na economia brasileira, as "máquinas do crescimento schumpeterianas" da quinta revolução tecnológica.

Portanto, a instituição da estratégia "desenvolvimentista internacionalista" condicionou o Brasil a um padrão de baixo dinamismo econômico no longo prazo. O passado começou a cobrar do presente os 25 anos em que a estratégia de desenvolvimento delegou ao capital estrangeiro o papel de agente transformador e financiador do crescimento.

\section{REFERÊNCIAS BIBLIOGRÁFICAS}

AMSDEN, A. H. (2001) "National firms leaders", in The Rise of the Rest. New York: Oxford University Press, cap. 8.

AREND, Marcelo (2009) 50 Anos de Industrialização do Brasil (1955-2005): uma Análise Evolucionária. Tese de Doutorado em Economia, Porto Alegre, UFRGS.

BANCO CENTRAL DO BRASIL (2008) Séries Temporais de Economia e Finanças. Sistema gerenciador de séries temporais (SGS) - v1.3.2 - Módulo Público. Disponível em: <https://www3.bcb.gov. br/sgspub/localizarseries/localizarSeries.do?method=prepararTelaLocalizarSeriesttp >. Acesso em: 15 fev. 2008.

BRESSER-PEREIRA, L. C. (2007) Macroeconomia da Estagnação. São Paulo: Editora 34.

CASSIOLATO, J. E. (2001) “Que futuro para a indústria brasileira?”, in O Futuro da Indústria: Oportunidades e Desafios: A Reflexão da Universidade. Brasília: MDIC/STI/IEL Nacional, cap. 1.

CASSIOLATO, J. E.; LASTRES, H. M. M. (2005) “Tecnoglobalismo e o papel dos esforços de P,D\&I de multinacionais no mundo e no Brasil”, Parcerias Estratégicas, Brasília, n. 20, pp. 1225-1245.

CHANG, Ha-Joon (2009) Maus Samaritanos: O Mito do Livre Comércio e a História Secreta do Capitalismo. Rio de Janeiro: Elsevier.

CURADO, M. L. (1997) Investimento estrangeiro direto e industrialização no Brasil. Dissertação de Mestrado em Desenvolvimento Econômico, Faculdade de Ciências Econômicas, Universidade Federal do Paraná.

FEIJÓ, C. A.; CARVAlHO, P. G. M. (2008) A Evolução da Estrutura Industrial. São Paulo: IEDI, set. 2008. 27 p. Disponível em: <http://www.iedi.org.br/admin_ori/pdf/20060804_ide.pdf>. Acesso em: 15 nov. 2008.

FEIJÓ, C. A.; CARVAlHO, P. G. M.; ALMEIDA, J. S. G. (2005) Ocorreu uma Desindustrialização no Brasil? São Paulo: IEDI, nov. 2005. 31 p. Disponível em: <http://www.iedi.org.br/admin_ori/ pdf/20051129_desindustrializacao.pdf>. Acesso em: 5 jan. 2007.

GERSCHENKRON, A. (1962) Economic Backwardness in Historical Perspective. Cambridge, Massachusetts: Harvard University Press.

INSTITUTO DE PESQUISA ECONÔMICA APLICADA (2008) Ipeadata macroeconômico. Disponível em: <http://www.ipeadata.gov.br/ipeaweb.dll/ipeadata?Tick=133587765>. Acesso em: 22 mar. 2008.

KINDLEBERGER, C. P. (1992) Manias, Pânicos e Craches: Um Histórico das Crises Financeiras. Porto Alegre: Ortiz.

LAPLANE, M. (1992) O complexo eletrônico na dinâmica industrial dos anos oitenta. Tese de Douto- 
rado em Economia, Programa de Pós-Graduação em Economia, Instituto de Economia, Universidade Estadual de Campinas, Campinas.

NONNENBERG, Marcelo José Braga (2003) "Determinantes dos investimentos externos e impactos das empresas multinacionais no Brasil - as décadas de 1970 e 1990". Texto para discussão n ${ }^{\circ}$ 969, IPEA.

PALMA, J. G. (2005) “Quatro fontes de 'desindustrialização' e um novo conceito de 'doença holandesa”, in Conferência de Industrialização, Desindustrialização e Desenvolvimento, 2005, São Paulo. Anais eletrônicos. São Paulo: FIESP/IEDI. Disponível em: <http://www.fiesp.com.br/download/publicacoes_economia/jose_gabriel_palma.pdf>. Acesso em: 10 ago. 2007.

PEREZ, C. (2004) Revoluciones Tecnológicas y Capital Financiero: La Dinámica de las Grandes Burbujas Financieras y las Épocas de Bonanza. México: Siglo XXI.

SERRA, J. (1982) "Ciclos e mudanças estruturais na economia brasileira do Pós-Guerra”, in Belluzzo, L. G. M.; COUTINHO, R. (orgs.). Desenvolvimento capitalista no Brasil. São Paulo: Brasiliense.

SICSÚ, J.; PAULA, L. F.; MICHEL, R. (2007) “Por que novo desenvolvimentismo?”, Revista de Economia Política, v. 27, n. 4, pp. 507-524.

SILVA, A. X. (2006) Poupança externa e crescimento: uma análise sobre a experiência brasileira entre 1955 e 2004. Dissertação de Mestrado em Economia, Programa de Pós-Graduação em Economia, Instituto de Economia, Universidade Estadual de Campinas, Campinas.

VERSIANI, F.; SUZIGAN, W. (1990) “O processo brasileiro de industrialização: uma visão geral”, in Congresso Internacional de História Econômica, 10. 